Georgieva Lora, Żołądkiewicz Katarzyna, Zukow Walery. Vitamin D concentration in health care and sport performance. Pedagogy and Psychology of Sport. 2018;4(2):53-70. elSSN 2450-6605.

Original text

Georgieva Lora, Żolądkiewicz Katarzyna, Zukow Walery. Vitamin D concentration in health care and sport performance. Journal of Education, Health and Sport. 2018;8(2):53-70. eISSN 2391-8306. DOI http://dx.doi.org/10.5281/zenodo.1166140 http://ojs.ukw.edu.pl/index.php/johs/article/view/5253

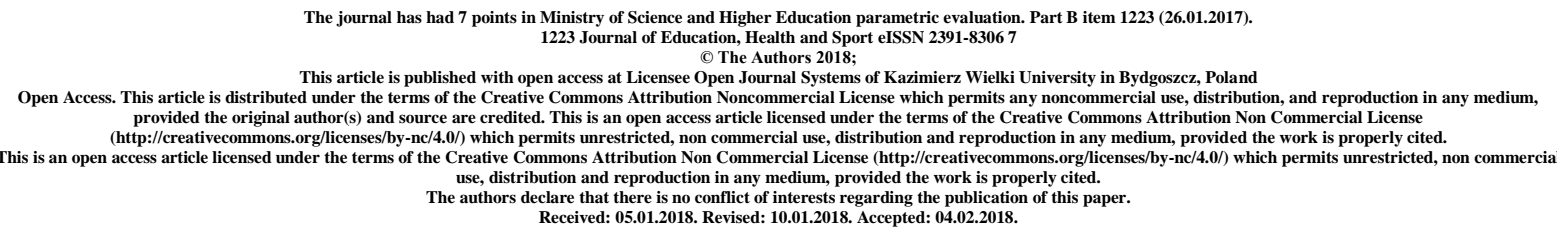

\title{
Vitamin D concentration in health care and sport performance
}

\author{
Lora Georgieva' ${ }^{1}$, Katarzyna Żołądkiewicz $^{2}$, Walery Zukow ${ }^{3}$
}

${ }^{1}$ Varna, Bulgaria

${ }^{2}$ Institute of Physical Culture, Faculty of Physical Education, Health and Tourism, Kazimierz Wielki University in Bydgoszcz, Poland

${ }^{3}$ Department of Spatial Management and Tourism, Faculty of Earth Sciences, Nicolaus Copernicus University, Torun, Poland 
Corresponding author:

Lora Georgieva

Lora Georgieva <lora.g.vn@gmail.com> 


\begin{abstract}
The molecular structure of Vitamin D is closely allied to that of classical steroids such as cholesterol. Technically Vitamin D is a seco-steroid hormone. Vitamin D3 (cholecalciferol) is normally produced by exposure to sunlight of the precursor (7-dehydrocholesterol), present in the skin. Vitamin D supplementation vary between $200 \mathrm{IU}$ to $1000 \mathrm{IU}$. Serum levels of 25(OH)D are generally consider as a indicator of Vitamin D status.

Vitamin D plays an essential role in healthcare, related not only with developing and maintaining a healthy skeleton. Its adequate supplementation reduce even the risk of caries and oral infections. Furthermore Vitamin D as a steroid hormone, modulates many gene transcription and has anti-inflammatory and cardiovascular protective effect. Uncertainly low serum levels of 25(OH)D are associated with misbalance in lipid profile and dyslipidemia, sacropenia and muscle weakness. Its insufficiency is also a risk factor for enhanced reception of pain, risk of type 2 diabetes, and often falls occurrences.

Adequate Vitamin D status is protective against musculoskeletal disorders, infection disease, depression, diabetes mellitus, autoimmune diseases and neurocognitive dysfunctions.

In sport activities and athletic population adequate serum levels of $25(\mathrm{OH}) \mathrm{D}$ increase muscle strength, and physical performance, and should be monitored.
\end{abstract}

Key words: vitamin D; athletic performance; $25(\mathrm{OH}) \mathrm{D}$; supplementation; insufficiency; athlete 


\section{Introduction}

The molecular structure of Vitamin D is closely allied to that of classical steroids such as cholesterol.

Strictly, Vitamin D is a seco-steroid hormone. Seco-steroids are hormones, in which one of the rings of the cyclopentanoperhydrophenanthrenering structure of classic steroid, has undergone fission by breakage of a carbon-carbon bond. In the instance of Vitamin D (both Vitamin D3 and Vitamin D2) this is the 9,10 carbon-bond of ring B. A cholesterol derivative 7dehydrocholesterol (3-beta-hydroxycholestadiene-5(6)7) is pro vitamin D3, called also cholecalciferol. The chief structural prerequisite of Provitamin D3 to be classified as a sterol, is its ability to be converted, upon ultraviolet irradiation, to a Vitamin D3 (Figure 1.) [1].

Vitamin D3 (cholecalciferol) is normally produced by exposure to sunlight of the precursor (7-dehydrocholesterol), present in the skin. Only few foods contain high concentration of Vitamin D3: fatty fish such as salmon and sardines, milk, egg yolks, cod liver oil and liver [2].

In contrast Vitamin D2, which is produced via ultraviolet irradiation (a photochemical reaction) of sterol ergosterol (Provitamin D2 - 3-beta-hydroxy-24-methylcholestatrien$5(6), 7,22)$, cannot be produced by exposure of skin to sunlight. It is phyto-sterol with 28 carbon atoms. All of these sterols are found in plant sources. Ergosterol is (Provitamin D2) is isolated firstly from ergot and yeast fungi, but usually it is obtained from beer-yeast and mushrooms $[2][3][8]$.

To be active, Vitamin D3 undergoes two hydroxylations. First, it is converted to 25hydroxyvitamin D3 (25(OH)D3) in the liver. Then, to 1-alpha,25hydroxyvitamin D3 (1alpha,25(OH)2 D3) in the kidney. The classical function of 1-alpha,25(OH)2 D3 is regulation of calcium homeostasis [4]. However, Vitamin D receptor (VDR) is expressed in tissues not involved in calcium metabolism, which mean it takes part in the regulation of many noncalcemic function [5]. Adipose tissue is an important metabolic organ. It has an essential role in energy balance and glucose homeostasis. It is the main storage site for Vitamin D. It also expresses VDR and enzymes involved in Vitamin D metabolism [6]. Recent research has demonstrated, that Vitamin D3 is active in adipocytes. It interact with membrane receptors, adaptor molecules, phosphatases, and nuclear co-regulator proteins. Therefore, it participates in the control of gene expression as well as cell signaling. Although peroxisome proliferator- 
activated receptor (PPAR) and Vitamin D signaling pathways regulate a multitude of gene involved in different physiological function [7].
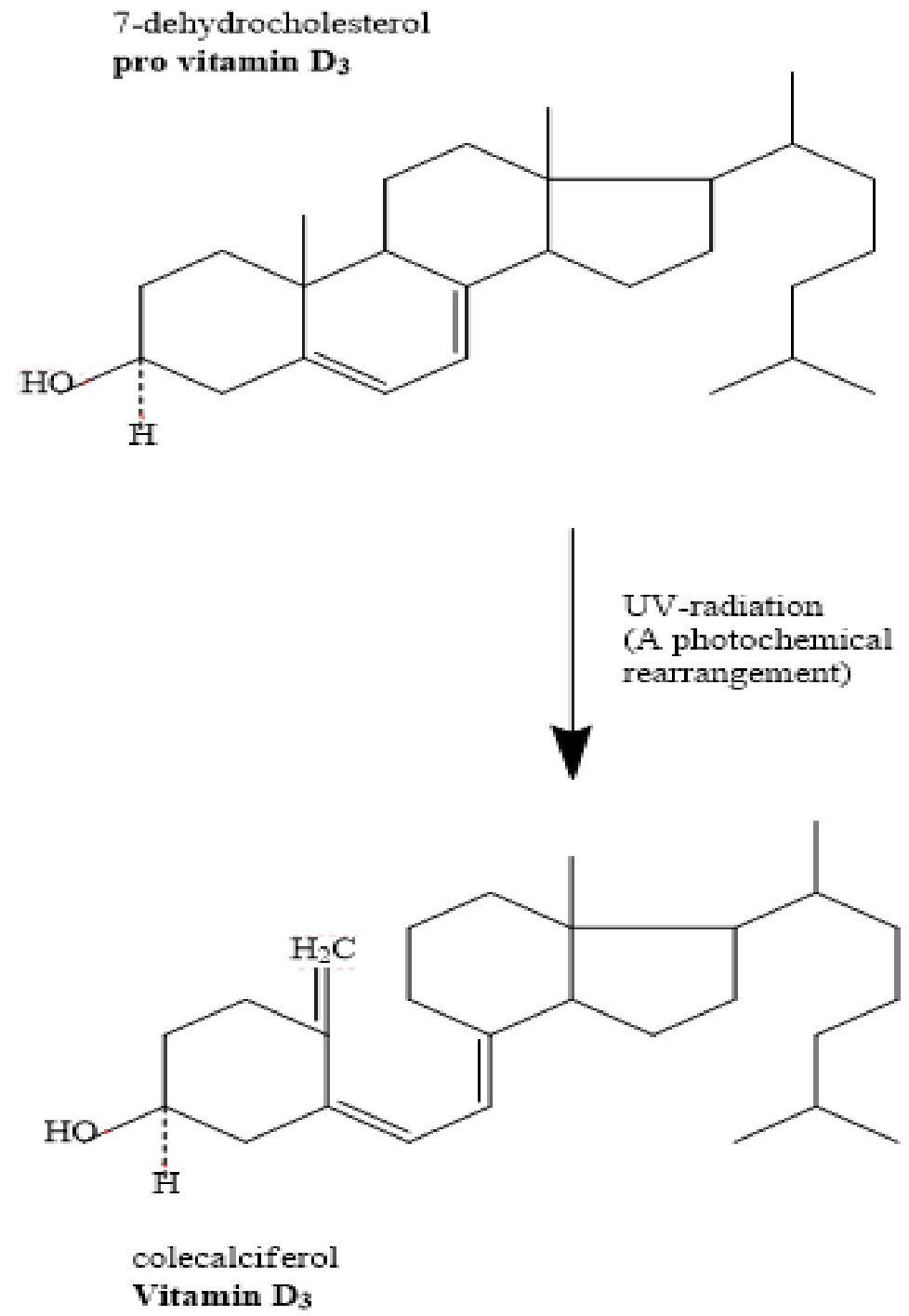

Figure 1. Provitamin D3 ultraviolet irradiation.

It has been shown that Vitamin D3 is from $60 \%$ to $80 \%$ more potent than Vitamin D2 in elevating serum 25(OH)D concentration. Moreover Vitamin D2 up-regulates the hepatic 24hydroxylase involved in the degradation of both the D2 and D2 forms of $25(\mathrm{OH}) \mathrm{D}$, causing a shortening of 25(OH)D3 half-time. For this reason, more reviews are focused on Vitamin D3 discussions [2].

Recently, a relationship between Vitamin D deficiency and reduced muscle strength has been observed. Vitamin D receptors have been found on skeletal muscle fibers, and studies have 
shown that these receptors are involved in protein synthesis within the muscle, promoting muscle growth [8].

\section{Supplementation}

The most safe and effective dose of Vitamin D supplementation for healthy adolescents is currently unknown [9]. There are many different randomized clinical trials about the most effective, safety and efficient dose. It vary between 200 IU to 1000 IU. Many studies suggest that a dose of $1000 \mathrm{IU}$ is required to ensure adequate serum $25(\mathrm{OH}) \mathrm{D}$ levels for skeletal and overall health [10][11][12]. Before years there is a data, that intake of Vitamin D in children and adolescents was 200 IU daily [13]. The American Academy of Pediatrics recommends a Vitamin D supplementation dose of 400 IU in healthy adolescents based on 2008 published guidelines[14]. More recently IOM proposed daily allowance of $600 \mathrm{IU}$ for healthy individuals age 1-70 years [15]. But signs of Vitamin D intoxication or PTH suppression did not occur with even 1000 IU dose [9].

$25(\mathrm{OH}) \mathrm{D}$ is generally considered as the best indicator of Vitamin D status, however, definite thresholds for Vitamin D status are not clear. Values commonly accepted as reference range are <50nmol/L, considered as deficiency; <80nmol/L, considered as insufficiency, and $>375 \mathrm{nmol} / \mathrm{L}$, considered as toxic. Optimal concentration are not yet well determined, but the optimal status is commonly consider to be between 100nmol/L and 175nmol/L [16].

Vitamin D intoxication are rare event. Excessive Vitamin D intake is present with risk of kidney problems, hypercalcemia and hypercalciuria, symptoms such: poor appetite, weight loss, abdominal pain, vomiting, constipation, polyuria and polydipsia, and in severe cases, lifethreatening dehydration [17]. For that, it should be a monitoring of clinical symptoms as well as serum 25(OH)D and calcium levels.

Studies have yielded conflicting data with regard to the optimal dose of Vitamin D supplementation for healthy adolescents. The differing results may be related to multiple potential confounding factors, such as sunlight exposure leading to cutaneous Vitamin D synthesis, difficulty ensuring compliance in adolescent subjects, and differences in dietary Vitamin D intake [9]. 


\section{Role of Vitamin D in healthcare}

Vitamin D plays an essential role in developing and maintaining a healthy skeleton for humans and other land vertebrates. The major biological function of $25(\mathrm{OH}) \mathrm{D}$ is to keep the serum calcium and phosphorus concentrations within the normal range. It is essential in maintaining cellular functions and, enzymatic activities, and promoting mineralization of skeleton [18]. Associations have been reported between vitamin D intake and risks of osteoporosis, multiple sclerosis, rheumatoid arthritis and cancer [19].

Low levels of $25(\mathrm{OH}) \mathrm{D}$ determine a decrease of intestinal absorption and in the blood calcium concentration, causing an increase in the level of parathyroid hormone [PTH], and thisin turn-causes an increase of bone turnover and therefore an increase in the risk of fracture [20]. Low levels of 25(OH)D are associated with alterations in balance [21], falls [22], fractures [23], and pain [24]. All this may contribute to a sedentary lifestyle and immobility, and therefore, to frailty [25][26].

Vitamin D`s role in reducing the risk of dental caries has been explored [27]. Other studies have linked Vitamin D deficiency to periodontal disease [28] and premature tooth loss [29]. Indirect bactericidal effect of Vitamin D may manifest via the induction of cathelicidin in reducing oral infections [30]. Nevertheless, it is more likely that low Vitamin D levels could be a marker for poor oral hygiene, malnutrition, and reflect a low socio-economic state [31].

Vitamin $\mathrm{D}$ is steroid hormone, which modulates gene transcription by binding a nuclear receptor found in numerous tissues. One of the genes regulated by Vitamin D is renin [32]. Vitamin D act an endogenous inhibitor of renin expression [33]. Evidence is also emerging with reference to associations between Vitamin D deficiency and an increase incidence of cardiovascular mortality and all-cause mortality [34]. Vitamin D has anti-inflammatory and cardiovascular protective effects [35]. Its cardiovascular protective effects are mediated through lowering blood pressure and vascular tone [36], preventing vascular calcification, improving cardiac and smooth muscle cell function, and maintaining the health of the endothelium [37]. Vitamin D improve not only left ventricular structure, but also functional parameters of contractility and relaxation [38][39]. In a recent report, the correction of Vitamin D deficiency and hypocalemia resulted in control of incessant ventricular tachycardia and cardiomyopathy. There is a possible role of Vitamin D deficiency as a casual factor for arrhythmia [40]. There is a data from researching experiment with mice with genetic deficiency of activity, from loss of 
either the Vitamin D receptor or the or 1-alpha-hydroxylase enzyme (which converts 25-hydroxy provitamin D to Vitamin D), develop hypertension and ventricular hypertrophy [41].

The relationship between lipid profiles, Vitamin D and biomarkers of cardiovascular disease risk has clear clinical and public health implication.[42]. Studies have shown that an altered lipid profile characterized by high concentration of atherogenic factors, such as high LDL- and TG concentration, and low HDL concentration during gestation, might increase risk of cardiovascular diseases. This may also result in undesirable outcomes for the mother and fetus [43][44]. Vitamin D may be an important modifiable risk factor. Studies in humans have shown that Vitamin D adequacy might be related to improvements in the lipid profile [45][46]. Serum levels of $25(\mathrm{OH}) \mathrm{D}$ are inversely correlated with very low density lipoprotein and triglyceride levels [47]. Vitamin D deficiency may cause an abnormal lipid profile by increasing peripheral insulin resistance and contributing to metabolic syndrome [48]. Uncertainly low level of 25(OH)D is repeatedly associated with dyslipidemia [49].

Vitamin D insufficiency is a risk factor for enhanced reception of pain [31]. Based on a number of data sets, a mechanistic link has been established between hypovitaminosis D and diabetic neuropathy, as well as certain pain symptoms such as: arthritic pain, rheumatism and fibromyalgia., in the general population [50]. Several observational studies have reported the effects of Vitamin D in reducing the risk of type 2 diabetes (T2D) [51][52][53]. Release of insulin including secretion in response to glucose from pancreatic beta-cells, at least in part seems to be dependent on Vitamin D adequacy. Having physiological blood levels of Vitamin D reduces the overproduction and tissue-damage caused by free radicals and blocks renin production [54]. This result in decreased islet cells harm from the effect of hyperglycemia and insulin resistance [55]. In addition, in person with T2D, short-term, daily supplementation of Vitamin D reduces central obesity and T2D, particularly in the carries of the AA genotype [56]. However, it is postulated that sufficient Vitamin D status has a beneficial influence on glucose tolerance in nondiabetic, weight-stable adults. These observations are independent of body mass, suggesting that there are direct effect of Vitamin D on glucose-controlling tissues [57].

Aging is also a risk factor for Vitamin D insufficiency [58], defined as a serum 25(OH)D concentration less than 50nmol/L [59]. Aging is accompanied by a shift in body composition toward the increase in fat mass and a decrease in skeletal muscle mass [60]. The loss of muscle mass and function termed sacropenia, is associated with physical impairment and disability 
[61][62]. Serum 25(OH)D is positively associated with muscle function [63][64], independent of physical activity. Older adults with Vitamin D insufficiency are reported to be more likely to develop sacropenia or proximal myopathy compared with adults with sufficient Vitamin D status [65][66]. Vitamin D receptors has been identified in skeletal muscle [67] and Vitamin D deficiency causes rickets in children and osteomalacia in adults, resulting in proximal muscle weakness. There are some evidence, that Vitamin D and leucine-enriched whey protein supplement improves muscle mass in sarcopenic older adults. Vitamin D may have enhanced the anabolic response causing the better uptake of leucine [68]. Muscle atrophy, particularly Vitamin D via type 2 fibers has been described histopathologically [69]. A dose of 800 IU/daily improves bone and muscle health and reduce the risk of falls and fractures [70].

Falls are a serious health problem of the aging population and start to increase after 60 years old, and even more in the 70`s and 80`s [71] About 25\%-30\% of the elderly women fall at last once a year and in those with a recent fall history more than $50 \%$ will fall again during the next year [72]. Falls have many consequences; injuries and fear of falling again restrict physical and social activities [73]. The idea of a medical treatment that can reduce falls has appeal and Vitamin D has been the most commonly studied opinion [74].

Several reports indicate an inverse relationship between Vitamin D deficiency and depression [75][76]. It`s deficiency worsens depression and mental health-related quality of life among women [77]. Vitamin D affect T- and B- lymphocyte activation, as well as quantity maturation and function of regulatory natural killer T-cells and their counterparts in the gut. Consequently, Vitamin D deficiency decreases innate and adaptive immunity, leading to persistent infections, chronic inflammation, and fatigue [78].

Researchers have found that there is a positive effect of Vitamin D supplementation combining with isokinetic training in the rehabilitation of burned children [6]. Burned patients are especially at risk of developing Vitamin D deficiency, because of low sunshine exposure, less skin capacity to synthesize Vitamin D, poorer absorption with less activation on the kidney and peripheral tissues, and fewer or lower expression of Vitamin D receptors in the peripheral tissues [79][80]. 


\section{Vitamin D concentration and sport}

Despite a wide number of studies performed on the general population, little is known about the Vitamin D status of athletes. Significant variation in serum $25(\mathrm{OH}) \mathrm{D}$ concentration have been found in the general population. Similar patterns have also been reported in relation to athletic population [81]. Training in-doors has a negative effect on serum 25(OH)D levels with insufficiencies reaching up to $80 \%$ compared to $48 \%$ in those training out-doors [82].

Serum $25(\mathrm{OH}) \mathrm{D}$ is an important hormone with a wide range of functions. Almost its deficiency has been shown to impair muscle action [83] and can lead to decrease in muscle strength, [84] particularly in the elderly, to whom most of the published work refers to. Bischoff et.al. [85] postulated the importance of exposure to sunlight to serum 25(OH)D levels, where institutionalized elderly demonstrated lower sunlight exposure and lower muscle strength compared to controls. Holick [81] and Hamilton [86] have noted that serum 25(OH)D deficiency has significant negative relationships with lower body power, performance [87] and grip strength [88] in adolescent girls. A systematic review on the elderly, concluded that Vitamin D supplementation alone improves physical performance and, in combination with calcium, could result in reduced falls [89].

A particular influence of many factors, including skin pigmentation, early- or late-day training, indoor training, geographic location and extensive sunscreen use, has been observed in the in the specific population. Athletes, who train indoors, especially during the winter are prone to serum $25(\mathrm{OH}) \mathrm{D}$ deficiency. There are results, that shown significant drop in average winter serum levels of $25(\mathrm{OH}) \mathrm{D}$, which was accompanied by a significant decrease in mean serum calcium and significant increase in mean serum PTH, in professional football players, both within the normal reference range [90]. The periodical measurement of Vitamin D serum levels is the only procedure capable to define athletes`status. There is a data, that suppose, at least 800 IU dosage of Vitamin D alone or in combination with calcium may confer for physical performance measures [2].

Several studies have reported performance improvement of athletes after exposure to artificial UVB. Cross-sectional studies also reported that $25(\mathrm{OH}) \mathrm{D}$ improves physical performance in elder people [91]. Studies conducted in older individuals show that vitamin D improves their functional capabilities [31]. Although the mechanism is not well understood, evidence suggests a direct association between increasing body mass index (BMI) and Vitamin 
D insufficiency in adults [92]. Vitamin D deficiency has been related to muscle weakness and to Insulin Like Growth Factor Binding Protein3 (IGFBP3). A Vitamin D and acute exercise merge is proposed to modify the IGF system [93] The Insulin-Like Growth Factor (IGF) system has implications in physical activity and exercise [94], and more recently in its relationship to Vitamin D. Physical activity alone is correlated with decreases in disease, as are sufficient levels of Vitamin D [95]. Its adequacy may sustain performance ability.

Vitamin D supplementation have a significant effect on upper limb muscle strength. It was found that it improves upper and lower muscle strength in a healthy adults, athletic and nonathletic population between the age of 18 and 40 years old [8]. Vitamin D supplementation combined with an isokinetic training program increase quadriceps muscle strength and Vitamin D levels [96]. It has also been postulated, that Vitamin D improves physical performance measures such as muscle power and contraction speed [97]. In addition, Vitamin D affects neural coordination and control on neuromuscular system, and there is growing evidence showing that vitamin $\mathrm{D}$ has a neurotrophic effect on body [98].

\section{Conclusion}

Vitamin D serum concentration is essential for normal body state and its stage is positively correlated with health status. It is related with many biological process, not only with skeletal and muscle system, but also with cardio-vascular and endocrine system. Vitamin D serum concentration is co-related with lipid profile, aging and risk of falls and is widely used for preventing of many disease, such as diabetes, cardio-vascular problems, depression. Moreover it takes a part in regulation of essential elements and it support recuperation after some inflammation process.

Vitamin D supplementation should be a part of daily-diet specially in group of active sport-training populations. Coaches and medical staff should consider monitoring serum 25(OH)D levels in their athletes throughout the year macrocycles, and especially during the winter months to prevent its decrease.

\section{References}

[1] Norman, A.W., Bouillon, R. (2010). Vitamin D nutritional policy needs a vision for the future., Exp. Biol. Med. 235, 1034-1045. 
[2] Lanteri, P., Lombardi, G., Colombini, A., Banfi, G. (2013). Vitamin D in exercise: Physiologic and analytical concerns., Clinica Chimica Acta 415, 45-53.

[3] Haussler, M.R., Jurutka, P.W., Mizwicki, M., Norman, A.W. (2011). Vitamin D receptor (VDR)-mediated actions of lalpha,25(OH)2vitamin D3: genomic and non-genomic mechanisms., Best Pract. Res. Clin. Endocrinol. Metab. 25, 543-559.

[4] DeLuca, H.F. (2004) Overview of general physiologic features and functions of vitamin D., Am. J. Clin. Nutr. 80 (Suppl), 1689S-1696S.

[5] Nagpal, S., Na, S., Rathnachalam, R. (2005). Noncalcemic actions of vitamin D receptor ligands., Endocr. Rev. 26 (5), 662-687, doi:http://dx.doi.org/10.1210/er.2004-0002.

[6] Li, J., Byrne, M.E., Chang, E., et al. (2008). 1 alpha,25-Dihydroxyvitamin D 3 hydroxylase in adipocytes., J. Steroid Biochem. Mol. Biol. 112 (1-3), 122-126, doi: http://dx.doi.org/10.1016/j.jsbmb.2008.09.006.

[7] Ryynänen, J., Neme, A., Tuomainen, T.-P., et al. (2014). Changes in vitamin D target gene expression in adipose tissue monitor the vitamin $D$ response of human individuals., Mol. Nutr. Food Res. 58, 2036-2045, doi: http://dx.doi.org/10.1002/mnfr.201400291.

[8] Tomlinson, P.B., Joseph, Angioi, C.M. (2015). Effects of vitamin D supplementation on upper and lower body muscle strength levels in healthy individuals. A systematic review with meta-analysis., Journal of Science and Medicine in Sport 18, 575-580.

[9] Putman M.S., Pitts, S.A., Milliren, C.E., et. al. (2013). A Randomized Clinical Trial of Vitamin D Supplementation in Healthy Adolescents., Journal of Adolescent Health 52, 592e598.

[10] Vieth, R. (2006). What is the optimal vitamin D status for health?., Prog Biophys Mol Biol 92:26e32.

[11] Heaney, R.P. (2008) Vitamin D: Criteria for safety and efficacy., Nutr Rev 66-(Suppl 2):S178e81.

[12] Cheng, S, Tylavsky, F, Kroger H, et al.(2003). Association of low 25-hydroxyvitamin D concentrations with elevated parathyroid hormone concentrations and low cortical bone density in early pubertal and prepubertal Finnish girls., Am J Clin Nutr 78:485e92.

[13] Institute of Medicine (1997). Dietary Reference Intakes for Calcium, Phosphorus, Magnesium, Vitamin D, and Fluoride., Washington, DC: The National Academic Press.

[14] Wagner, C.L., Greer, F.R. (2008). Prevention of rickets and vitamin D deficiency in infants, children, and adolescents., Pediatrics 122:1142e52.

[15] Institute of Medicine (2011). Dietary Reference Intakes for Calcium and Vitamin D. Washington, DC: The National Academic Press.

[16] Larson-Meyer, D.E., Willis, K.S.(2010) Vitamin D and athletes., Curr Sports Med Rep 9:220-6. 
[17] Verkaik-Kloosterman, J., Seves, S.M., Ocké, M.C. (2017). Vitamin D concentrations in fortified foods and dietary supplements intended for infants: Implications for vitamin D intake., Food Chemistry 221, 629-635.

[18] Holick, M.F. (1996). Vitamin D and bone health., J. Nutr. 126 (4 Suppl), 1159S-1164S.

[19] Suzuki, T., Kwon, J., Kim, H., et al. (2008). Low serum 25-hydroxyvitamin D levels associated with falls among Japanese community-dwelling elderly., J. Bone Miner. Res. 23 (8), 1309-1317.

[20] Lips, P. (2006). Vitamin D physiology., Prog. Biophys. Mol. Biol. 92, 4-8.

[21] Zamboni, M., Zoico, E., Tosoni, P., et al. (2002). Relation between vitamin D, physical performance, and disability in elderly persons., J. Gerontol. Ser. A: Biol. Sci. Med. Sci. 57, M7M11.

[22] Snijder, M.B., van Schoor, N.M., Pluijm, S.M., van Dam, R.M., Visser, M., Lips, P. (2006). Vitamin D status in relation to one-year risk of recurrent falling in older men and women., J. Clin. Endocrinol. Metab. 91, 2980-2985.

[23] Lips, P. (2001). Vitamin D deficiency and secondary hyperparathyroidism in the elderly: consequences for bone loss and fractures and therapeutic implications., Endocr. Rev. 22, 477501.

[24] Mascarenhas, R., Mobarhan, S. (2004). Hypovitaminosis D-induced pain., Nutr. Rev. 62, 354-359.

[25] Puts, M.T., Visser, M., Twisk, J.W., Deeg, D.J., Lips, P. (2005). Endocrine and inflammatory markers as predictors of frailty., Clin. Endocrinol. (Oxf.) 63, 403-411.

[26] Artaza-Artabe, I., et. al. (2016). The relationship between nutrition and frailty: Effects of protein intake, nutritional supplementation, vitamin $D$ and exercise on muscle metabolism in the elderly. A systematic review., Maturitas 93, 89-99.

[27] Mellanby, M., Pattison, C.L., (1928). The action of Vitamin D in preventing the spread and promoting the arrest of caries in children., Br. Med. J. 2 (3545) 1079-1082.

[28] Alshouibi, E.N., Kaye, E.K., Cabral, H.J., Leone, C.W., Garcia, R.I. (2013). Vitamin D and periodontal health in older men., J. Dent. Res. 92 (8), 689-693.

[29] Krall, E.A, Wehler, C., Garcia, R.I., Harris, S.S., Dawson-Hughes, B. (2001). Calcium and vitamin D supplements reduce tooth loss in the elderly., Am. J. Med. 111 (6), 452-456.

[30] Grant, W.B. (2011). A review of the role of solar ultraviolet-B irradiance and vitamin $D$ in reducing risk of dental caries., Dermatoendocrinology 3 (3), 193-198.

[31] Wimalawansa, S.J. (2016). Non-musculoskeletal benefits of vitamin D., Journal of Steroid Biochemistry \& Molecular Biology, http://dx.doi.org/10.1016/j.jsbmb.2016.09.016. 
[32] Deepak, K., Gupta, M.D., Thomas, J., Wang, M.D. (2016). A Role for Vitamin D Supplementation?, Journal of the American college of Cardiology 67, 22, http://dx.doi.org/10.1016/j.jacc.2016.04.012.

[33] Li, Y.C., Kong, J., Wei, M., Chen, Z.F., Liu, S.Q., Cao, L.P. (2002). 1,25-Dihydroxyvitamin $D(3)$ is a negative endocrinesystemic regulator of the renin-angiotensin system., J Clin Invest 110:229-38.

[34] Semba, R.D., Houston, D.K., Bandinelli, S., et al. (2010). Relationship of 25hydroxyvitamin $D$ with all-cause and cardiovasculardisease mortality in older communitydwelling adults., Eur. J. Clin. Nutr. 64 (2), 203-209.

[35] Chen, Y., Kong, J., Sun, T., et al. (2011) 1,25-Dihydroxyvitamin D3 suppresses inflammation-induced expression of plasminogen activator inhibitor-1 by blocking nuclear factor-kappaB activation., Arch. Biochem. Biophys. 507 (2), 241-247.

[36] Timms, P.M., Mannan, N., Hitman, G.A., et al. (2002) Circulating MMP9, vitamin D and variation in the TIMP-1response with VDR genotype: mechanisms for inflammatory damage inchronic disorders?, QJM 95 (12), 787-796.

[37] Somjen, D., Weisman, Y., Kohen, F., et al. (2005). 25-hydroxyvitamin D3-1alphahydroxylase is expressed in human vascular smooth muscle cells and is upregulated by parathyroid hormone and estrogenic compounds., Circulation 111 (13), 1666-1671.

[38] Bodyak, N., Ayus, J.C., Achinger, S., et al. (2007) Activated vitamin D attenuates left ventricular abnormalities induced by dietary sodium in Dahl salt-sensitive animals., Proc Natl Acad Sci USA 104:16810-5.

[39] Green, J.J., Robinson, D.A., Wilson, G.E., et al. (2006). Calcitriol modulation of cardiac contractile performance via protein kinase., C. J Mol Cell Cardiol, 41:350-9

[40] Chavan, C.B., Sharada K., Rao, H.B., Narsimhan, C. (2007). Hypocalcemia as a cause of reversible cardiomyopathy with ventricular tachycardia., Ann Intern Med, 146:541-542

[41] Xiang, W., Kong, J., Chen, S., et al. (2005). Cardiac hypertrophyin vitamin D receptor knockoutmice: role of the systemic and cardiacrenin-angiotensin systems., Am J Physiol Endocrinol Metab; 288:E125-32.

[42] Lepsch, J., Eshriqui, I., Farias, D.R.., el. al. (2017). Association between early pregnancy vitamin D status and changes in serum lipid profiles throughout pregnancy., Metabolism Clinic and Experimental 70, 85-9.

[43] Charlton, F., Tooher, J., Rye, K.A., Hennessy, A. (2014). Cardiovascular risk, lipids and pregnancy: preeclampsia and the risk of later life cardiovascular disease., Heart Lung Circ 23:203-12.

[44] Emet, T., Ustüner, I., Güven, S.G., et al. (2013). Plasma lipids and lipoproteins during pregnancy and related pregnancy outcomes., Arch Gynecol Obstet, 288:49-55. 
[45] Carbone, L.D., Rosenberg, E.W., Tolley, E.A., et al. (2008). 25- Hydroxyvitamin D, cholesterol, and ultraviolet irradiation., Metabolism, 57:741-8.

[46] Lee, S., Ahuja, V., Masaki, K., Evans, R.W., Barinas-Mitchell, E.J., Ueshima, H. (2016). A significant positive association of vitamin $D$ deficiency with coronary artery calcification among middle-aged men: for the ERA JUMP study., J Am Coll Nutr, 17:1-7.

[47] Lind, L., Hanni, A., Lithell, H., Hvarfner, A., Sorensen, O.H., Ljunghall, S. (1995). Vitamin $D$ is related to blood pressure and other cardiovascular risk factors in middle-aged men., Am J Hypertens, 8:894-901.

[48] Reddy Vanga, S., Good, M., Vacek, J.L. (2010) Role of Vitamin D in Cardiovascular Health., Am J Cardiol, 106:798-805

[49] Farid, K.F., Zhao, D., Martin, S.S. et. al. (2017). Serum vitamin D and change in lipid levels over 5 y: The Atherosclerosis Risk in Communities study., Nutrition 38, 85-93

[50] Hirani, V. (2012). Vitamin D status and pain: analysis from the Health Survey for England among English adults aged 65 years and over., Br. J. Nutr. 107 (7), 1080-1084.

[51] Parker J.H.O., Dutton, D., Mavrodaris, A., Stranges, S., Kandala, N.B., Clarke, A., Franco, O.H. (2010). Levels of vitamin D and cardiometabolic disorders: systematic review and metaanalysis., Maturitas 65, 225-236.

[52] Afzal, S., Bojesen, S.E., Nordestgaard, B.G. (2013). Low 25-hydroxyvitamin D and risk of type 2 diabetes: a prospective cohort study and metaanalysis., Clin. Chem. 59(2), 381-391.

[53] Mitri J., Muraru, M.D., Pittas, A.G. (2011). Vitamin D and type 2 diabetes: a systematic review., Eur. J. Clin. Nutr. 65 (9), 1005-1015.

[54] Lee, D.M., Tajar, A., Pye, S.R., et al. (2012). Association of hypogonadism with vitamin d status: the european male ageing study., Eur. J. Endocrinol. 166 (1), 77-85.

[55] Tepper, S., Shahar, D.R., Geva, D., Ish-Shalom, S. (2016). Differences in homeostatic model assessment (HOMA) values and insulin levels after vitamin D supplementation in healthy men: a double-blind randomized controlled trial., Diabetes Obes. Metab. 18 (6), 633-637.

[56] Shab-Bidar, S., Neyestani, T.R., Djazayery, A. (2015). Vitamin D receptor Cdx-2-dependent response of central obesity to vitamin $D$ intake in the subjects with type 2 diabetes: a randomised clinical trial., Br. J. Nutr. 114 (9), 1375-1384.

[57] Kobza, V.M., Fleet, J.C., Zhou, J., et.al. (2013). Vitamin D status and resistance exercise training independently affect glucose tolerance in older adults., Nutrition Research 33, 349-357

[58] MacLaughlin, J., Holick, M.F. (1985). Aging decreases the capacity of human skin to produce vitamin D 3., J Clin Invest, 76(4):1536-8.

[59] Alvarez, J.A., Ashraf, A.P., Hunter, G.R., Gower, B.A. (2010). Serum 25-hydroxyvitamin D and parathyroid hormone are independent determinants of whole-body insulin sensitivity in 
women and may contribute to lower insulin sensitivity in African Americans., Am J Clin Nutr, 92(6):1344-9.

[60] Evans, W.J., Campbell, W.W. (1993). Sarcopenia and age-related changes in body composition and functional capacity., J Nutr, 123(2 Suppl):465-8.

[61] Baumgartner, R.N., Koehler, K.M., Gallagher, D., et al. (1998). Epidemiology of sarcopenia among the elderly in New Mexico., Am J Epidemiol, 147(8):755-63.

[62] Janssen, I., Heymsfield, S.B., Ross, R. (2002). Low relative skeletal muscle mass (sarcopenia) in older persons is associated with functional impairment and physical disability., $\mathrm{J}$ Am Geriatr Soc, 50(5):889-96.

[63] Dhesi, J.K., Bearne, L.M., Moniz, C., et al. (2002). Neuromuscular and psychomotor function in elderly subjects who fall and the relationship with vitamin D status., J Bone Miner Res, 17(5):891-7.

[64] Bischoff-Ferrari, H.A., Dietrich, T., Orav, E.J., et al. (2004). Higher 25-hydroxyvitamin D concentrations are associated with better lower-extremity function in both active and inactive persons aged $>$ or $=60$ years., Am J Clin Nutr, 80(3):752-8.

[65] Visser, M., Deeg, D.J., Lips, P. (2003). Low vitamin D and high parathyroid hormone levels as determinants of loss of muscle strength and muscle mass (sarcopenia): the Longitudinal Aging Study Amsterdam., J Clin Endocrinol Metab 2003;88(12):5766-72.

[66] Wicherts, I.S., van Schoor N.M., Boeke A.J., et al. (2007). Vitamin D status predicts physical performance and its decline in older persons., J Clin Endocrinol Metab, 92(6):2058-65.

[67] Bischoff, H.A., Borchers, M., Gudat, F., et al. (2001). In situ detection of 1,25dihydroxyvitamin D3 receptor in human skeletal muscle tissue. Histochem J, 33:19-24.

[68] Bauer, J.M., Verlaan, S., Bautmans, I., et.al. (2015). Effect of a Vitamin D and leucineenriched whey protein nutritional supplement on measures of sarcopenia in older adults, the PROVIDE study: a randomized, double-bind, placebo-controlled trail., J. Am Med Die Assoc 16:740-747, doi:10.1016/j.jamda.2015.05.021

[69] Ziambaras, K., Dagogo-Jack, S. (1997). Reversible muscle weakness in patients with vitamin D deficiency. West J Med, 167:435-9.

[70] Bischoff-Ferrari, H.A., Dawson-Hughes, B., Staehelin, H.B., et al. (2009). Fall prevention with supplemental and active forms of vitamin D: a meta-analysis of randomized controlled trials., BMJ 339, b3692.

[71] World Health Organization, WHO Global Report on Falls Prevention in Older Age, (2007).

[72] Close, J., Ellis, M., Hooper, R., Glickman, E., Jackson, S., Swift, C., (1999). Prevention of falls in the elderly trial (PROFET): a randomized controlled trial., Lancet 353 (9147), 93-97 (9). 
[73] Tinetti M.E, Williams, C.S. (1998). The effect of falls and fall injuries on functioning in community-dwelling older persons., J. Gerontol. A. Biol. Sci. Med. Sci. 53 (2), (M112-9).

[74] Smith L.M., Gallagher, J.C., Suiter, C. (2017). Medium doses of daily vitamin D decrease falls and higher doses of daily vitamin D3 increase falls: A randomized clinical trial., Journal of Steroid Biochemistry and Molecular Biology, http://dx.doi.org/10.1016/j.jsbmb.2017.03.015.

[75] Neupane, S.P., Lien, L., Hilberg, T., Bramness, J.G. (2013). Vitamin D deficiency in alcohol-use disorders and its relationship to comorbid major depression: a cross-sectional study of inpatients in Nepal, Drug Alcohol Depend., 133 (2), 480-485.

[76] Rastmanesh, R., Beauchet, O., Annweiler, C. (2012). Vitamin D deficiency and depression: causal relationship or artifact?, Biofactors 38 (5), 317-319.

[77] Moy, F.M., Hoe, V.C., Hairi, N.N., Vethakkan, S.R., Bulgiba, A. (2016). Vitamin D deficiency and depression among women from an urban community in a tropical country., Public Health Nutr, 1-7.

[78] Hock, A.D. (2014). Review: Vitamin D3 deficiency results in dysfunctions of immunity with severe fatigue and depression in a variety of diseases., In Vivo 28 (1), 133-145.

[79] Boonen, S., Bischoff-Ferrari, H.A., Cooper, C., et al. (2006). Addressing the musculoskeletal 464 components of fracture risk with calcium and vitamin D: a review of the evidence., Calcif Tissue Int 78:257-70.

[80] Dawson-Hughes, B. (2008). Serum 25-hydroxyvitamin D and functional outcomes in the elderly., Am J Clin Nutr 88:537S-40S.

[81] Holick, M. (2007). Vitamin D deficiency., N Engl J Med 357:266-281.

[82] Constantini, N., Arieli, R., Chodick, G., et al. (2010). High prevalence of vitamin D insufficiency in athletes and dancers., Clin J Sport Med 20(5):368-371.

[83] Solomon, A., Bouloux, P. (2006). Modifying muscle mass-the endocrine perspective., J Endocrinol 191:349-360.

[84] Houston, D., Tooze, J., Hauman, D., et al. (2011). Change in 25-hydroxyvitamin D and physical performance in older athletes., J Gerontol Ser A: Biol Sci Med Sci 66A:430-436.

[85] Bischoff, H., Stahelin, H., Urscheler, S., et al. (1999). Muscle strength in the eldery: is relation to vitamin D metabolites., Arch Phys Med Rehabil 80:54-58.

[86] Hamilton, B. (2010). Vitamin D and human skeletal muscle., Scand J Med Sci Sports, 20:182-190.

[87] Ward, K., Das, G., Berry, J. et al. (2009). Vitamin D status and muscle function in postmenarchal adolescent girls., J Clin Endocrinol Metab, 94:559-563. 
[88] Foo, L., Zhang, Q., Zhu, K., et al. (2009). Low vitamin D status has an adverse influence on bone mass, bone turnover, and muscle strength in Chinese adolescent girls., J Nutr, 139:10021007.

[89] Latham, N., Anderson, C., Reid, I. (2003). Effects of vitamin D supplementation on strength, physical performance and falls in older persons: a systematic review., J Am Geriatr Soc, 51:1219-1226.

[90] Galan, F., Ribas, J., Sánchez-Martinez, P.M., et.al. (2012). Serum 25-hydroxyvitamin D in early autumn to ensure vitamin D sufficiency in mid-winter in professional football players., Clinical Nutrition 31, 132e136

[91] Cannell, J.J., Hollis, B.W., Sorenson, M.B., Taft, T.N., Anderson, J.J. (2009). Athletic performance and vitamin D., Med. Sci. Sports Exerc. 41 (5), 1102-1110.

[92] Samuel, L., Borrell, L.N. (2013). The effect of body mass index on optimal vitamin D status in U.S. adults: The National Health and Nutrition Examination Survey 2001-2006., Annals of Epidemiology 23, 409e414

[93] Darr, R.L., Savage, K.J., Baker, M., et.al. (2016). Vitamin D supplementation affects the IGF system in men after acute exercise., Growth Hormone \& IGF Research 30-31, 45-51

[94] Suikkari, A.M.., Sane, T., Seppälä, M., et al. (1989). Prolonged exercise increases serum insulin-like growth factor-binding protein concentrations., J. Clin. Endocrinol. Metab. 68 (1), 141-144.

[95] Giovannucci, E., Liu, Y., Rimm, E.B., et al. (2006). Prospective study of predictors of vitamin D status and cancer incidence and mortality in men., J. Natl. Cancer Inst. 98 (7), 451459.

[96] Ebid, A.A., El-Shamy, S.M., Amer, M.A. (2017). Effect of vitamin D supplementation and isokinetic training on muscle strength, explosive strength, lean body mass and gait in severely burned children: A randomized controlled trial., Burns 43, 357-365

[97] Gmiat, A., Mieszkowski, J., Prusik, K., et. al. (2017). Changes in pro-inflammatory markers and leucine concentrations in response to Nordic Walking training combined with vitamin $D$ supplementation in elderly women. Biogerontology, 18(4), 535-548.

[98] Annweiler, C., Schott, A.M., Berrut, G., et. al. (2010). Vitamin D and ageing: neurological issues., Neuropsychobiology 62:139-50. 